the conclusions have been referred to in previous accounts of research work in this column. This report completes the first decade of operations on the mountain, and we are promised a brief outline of the work for this period. The past year is described as " one of the most productive of this period." We are told that solar research has progressed satisfactorily, that a beginning has been made in the application to solar phenomena of Stark's capital discovery of the effect of an electric field on radiation. One of the new conclusions in stellar astronomy promises to furnish the means of determining a star's distance simply by measuring its brightness and the relative intensities of certain lines in its spectrum. Laboratory investigations and the work of construction have gone. forward rapidly. With regard to the last-mentioned, it is hoped to complete the dome for the roo-in. reflecting telescope next summer, and to set up the mounting in the autumn. The large mirror has already received an almost perfectly spherical figure, and preparations are being made for the work of parabolising it. The reader must refer to the report itself to note the progress made in the many and various investigations which are in operation, both on the mountain and at the base station.

Annuatre Astronomigue et MétÉrologigue pour I915.- The fifty-first issue of the useful handbook entitled "Annuaire Astronomique et Météorologique" has just come to hand. M. Camille Flammarion, the originator and editor of this handy reference book, has, in spite of the recent difficulties met with in Paris, produced the volume up to the high standard of its predecessors. Most of the readers of this column know the arrangement and subjects of the contents so well that it seems necessary only to direct attention to the issue of the volume. Nevertheless it may be added that under the heading, "Scientific Notices," which is an annual review of the progress of astronomy, the reader will obtain a good broad view of the year's work, while in the numerous other sections dealing with the calendar, phenomena, astronomical tables, etc., illustrated by 120 figures of charts and diagrams, a mine of valuable material is included.

\section{THE AVEZZANO EARTHQUAKE OF JANUARY I3.}

F OR most of the details contained in the present paper I am indebted to the courtesy of Dr. G. Martinelli, of the Ufficio Centrale di Meteorologia e di Geodinamico at Rome, and of Dr. G. Agamennone, the well-known director of the Geodynamic Observatory of Rocca di Papa, near Rome.

The map of the isoseismal lines is a reproduction of that prepared by Dr. G. Martinelli from the numerous observations forwarded to the Central Office. The scale of intensity employed is that of the late Prof. Mercalli, which, in Italy, has superseded the RossiForel scale. The degree $\mathrm{X}$., for instance, represents the intensity of a shock capable of ruining many buildings and causing much loss of life; the degree VII. that of a shock that will throw down chimneys and produce slight cracks in numerous buildings; while the degree II. corresponds to a shock that can just be felt under favourable conditions by persons at rest. It will be seen that the isoseismal $\mathrm{X}$. is an elongated curve including Avezzano at its western end. The isoseismal of intensity VII, is interrupted by the eastern coast of Italy, and extends beyond Rome to within a few miles of the western coast. The isoseismal of intensity II., which represents the boundary of the disturbed area, includes Parma, Mantua, Verona, and Venice to the north, and to the south approaches within thirty miles of Messina. NO. 2368, VOL. 95]
Thus the area disturbed is not less than 550 miles in length. Its width is, of course, unknown, but, if the mean radius be taken as 275 miles, the total disturbed area must extend over about 240,000 square miles, an area about two-thirds of that shaken by the San Francisco earthquake of 1906.

Dr. Agamennone informs me that the first vibrations were registered at the Rocca di Papa Observatory at $6 \mathrm{~h}$. $52 \mathrm{~m}$. 54s. a.m. (G.M.T.), but the vibrations soon attained such strength that the seismographs there were thrown out of action. At Rome, a somewhat less sensitive seismograph registered the whole movement, though the pendular masses beat repeatedly against the screws which are arranged to protect the instrument from excessive oscillation. At Eskdalemuir, the first movement was recorded by the Galitzin seismograph at $6 \mathrm{~h} .56 \mathrm{~m} .45 \mathrm{~s}$. , and the beginning of the principal portion at $7 \mathrm{~h}$. $\mathrm{rm}$., the instrument remaining in motion until $9 h$. $12 \mathrm{~m}$. Judging

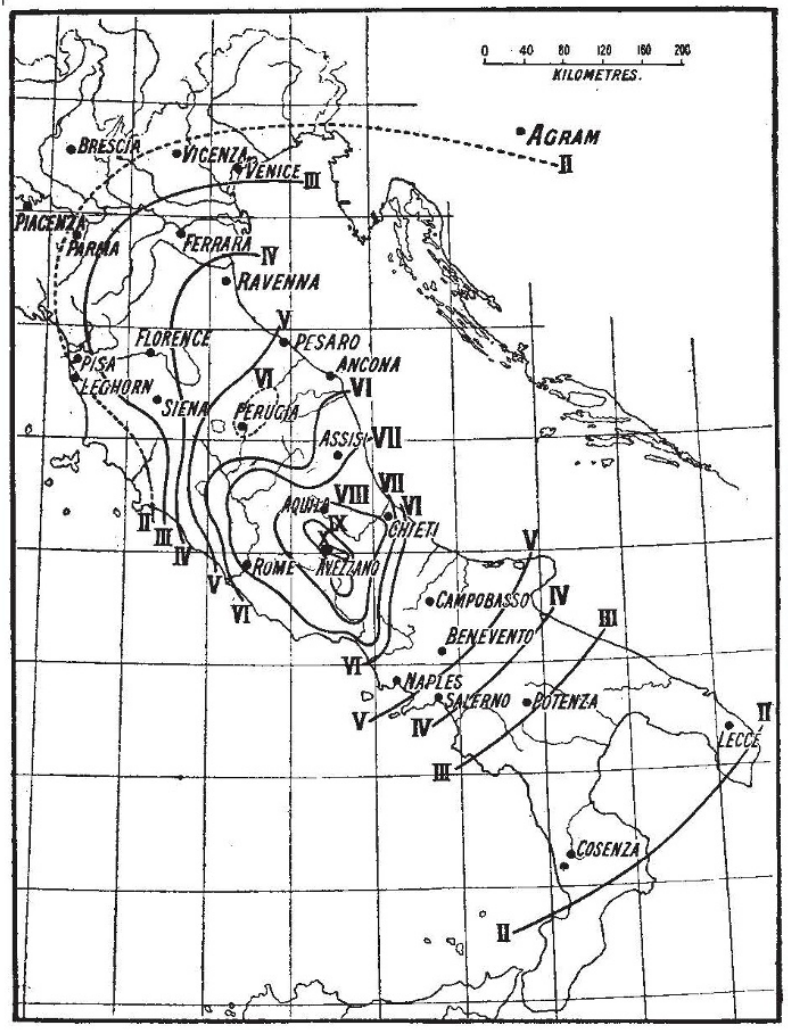

from the seismogram obtained at this observatory, the epicentre was at the distance of $1930 \mathrm{~km}$. in the direction $40^{\circ} 50^{\prime}$ south of east; that is, in $42^{\circ} \mathrm{N}$. lat., $14^{\circ} \mathrm{E}$. long. The centre of the isoseismal line of intensity $\mathrm{X}$. is in $42^{\circ} \mathrm{o}^{\prime} \mathrm{N}$. lat., $13^{\circ} 27^{\prime} \mathrm{E}$. long. According to a special seismological bulletin issued by the Georgetown (U.S.A.) University Department of Geology, the first tremors reached that place at 7 h. $28 \mathrm{~m}$. $40 \mathrm{~s}$., and the first oscillations of the principal portion at 7 h. $36 \mathrm{~m}$. $40 \mathrm{~s}$.

The Avezzano earthquake is noticeable tor its extraordinary number of after-shocks. At Rocca di Papa, a sensitive microseismograph was at work again an hour after the principal shock, and, from January I3-29, this instrument registered more than 500 aftershocks. That the earthquake was tectonic in its nature is indicated by the extensive disturbed area, the registration of the movement at great distances, and the unusual frequency of the after-shocks. 
The earthquake is being investigated by Dr. Mario Baratta on behalf of the Italian Geographical Society. A preliminary notice by Dr. G. Martinelli will appear in the next nuniber of the Bollettino of the Italian Seismological Society, and will include the map of the isoseismal lines reproduced here, and also a map prepared by Dr. Baratta to illustrate the seismic history of the district. From the latter, it is evident that the epicentral area of the recent earthquake, though not far distant from the imporfant seismic zone of Aquila, is one in which only earthquakes of slight intensity have originated in the past.

Since the above was written, a short paper on the earthquake by Dr. G. Agamennone has appeared in the Rendiconti of the R. Accad. dei Lincei (vol. xxiv., 1915, pp. 239-46). The author states that the most sensitive microseismometrograph at Rocca di Papa (about forty-three miles from the epicentre) recorded 240 after-shocks from 8.37 a.m. to midnight (that is, from 7.37 a.m. to II p.m., G.M.T.) on January I3, and on $\epsilon$ ach of the four succeeding days $120,88,38$, and 30 , the total number of after-shocks until February 6 being nearly 750, of which only about thirty were felt at the observatory or in the surrounding country.) Charles Davison.

\section{SANITATION IN INDIA. ${ }^{1}$}

$\mathrm{W}^{\mathrm{B}}$ have before us four volumes of papers presented to the All-India Sanitary Conference held at Lucknow in January of last year. Vol. ii. commences with an interesting account of the methods by which in Italy the silt of rivers is utilised for raising the level of the soil, while at the same time the level of the water is lowered by drainage. The system can be carried out with the primary object in view of reclaiming swampy land or the agricultural improvement can also be considered, an almost necessary procedure from the financial side. How far the method is applicable to India is a matter of great interest. One factor that has to be determined is the amount of silt in the particular river under consideration, and, secondly, if agricultural improvement is to be considered, whether the silt is of manurial value. The views of the agriculturist, the engineer, and the sanitarian all need consideration in a problem of this magnitude. How manifold and fundamental the problems are, a consideration of the papers dealing with malaria will show. It is indeed no little achievement that this immense malaria problem is now being studied in India in all its aspects, and that its solution has already progressed far from the facile position held not so long ago by many that the filling up of a few pools and ditches was the answer.

An anti-fly campaign was carried out in Delhi with considerable success, the methods employed being :(I) Either the burning of rubbish or covering it with one foot of earth; (2) the trenches of trenching grounds were cut $I \frac{1}{2} \mathrm{ft}$. deep and covered with a foot of earth well-rammed down; (3) the use of incineration at the latrines; $(4)$ the cleaning and sprinkling with pesterine of stables, cowsheds, backyards, etc.; (5) litter was removed daily or burned, bedding was changed at least once a week; (6) garden manure was not allowed to be exposed for more than four days-after this it must be dug into the ground and covered with a foot of earth; (7) butchers' shops and vegetable shops were dealt with; and (8) in private latrines, pucca floors and drains were made compulsory. The result of this campaign was that flies were "enormously reduced" and apparently the infantile mortality statistics. It

1 Supplement to the Indian Journal of Medical Research. Proceedings Igr. 19r4. Vol. ii., Papers, pp. ii+186. Vol. iii., Papers, pp. iv+220. Vol. iv. Spink and Co., rgr4.)

$$
\text { NO. } 2368 \text {, VOL. 95] }
$$

was not, however, until the breeding-grounds within the city-i.e. those comprised under headings (4) to (8) -were dealt with that progress was made.

In England the essential points in the bionomics of the fly have been known for some years, but flies still infest our large towns. Is it the inadequacy of the powers possessed by the sanitary authorities that allows this insane condition to continue, or is it the apathy that allows us also almost without a murmur to permit foul smoke to be discharged from our chimneys?

The section on conservancy contains. two interesting notes on the "pitting" of night soil, a simple and effective method of solving under certain conditions this ever-recurring problem. The essence of the method consists in sealing the pits from access of flies, etc., with road sweepings.

In vol. iii., the problems of tuberculosis and the very difficult one of a pure milk supply, water supply, notification of disease, and various questions in connection with sewage disposal, are discussed in several papers. An important one is the disposal of sewage sludge; the Grossman process in use in Oldham, where the sludge is dried and freed of its fat by passing steam through, yielding a valuable manure, seems successfully to solve the problem under certain conditions.

Vol. iv. The regulations for the control of malaria in Portuguese India are somewhat rigorous, e.g. all vessels intended to hold water will be closed and their contents changed at least every two days. Once a week at most is sufficient, as mosquitoes cannot develop from eggs in two days. Again, not only are ventilation outlets of drains to be furnished with wire gauze, but oil is to be poured into the openings to make assurance doubly sure, we suppose. A method for destroying larvæ that we do not remember to have seen mentioned before is contained in the following regulation. "Herds of animals will be introduced periodically (into ponds) to stir up the water, thus making it unsuitable for anopheline larvæ"!

In another paper figures are given which suggest that one species of malaria parasite prevails at one season of the year, another at another. If this is really so, and apparently similar results have been observed elsewhere, it would be important to know the reason for this.

A very interesting paper is that dealing with certain features of malaria in the island of Salsette. One main fact comes out, viz., that malaria increases as one approaches the hills. The study of the conditions in an island have always appeared to us especially interesting, and it is to be hoped that it can be repeated year after year. It shows clearly the great importance of an extended malaria survey of a district before houses are built anywhere and everywhere without consulting expert sanitary opinion.

Another interesting point is the effect of sea breezes in reducing the endemic index of malaria; "villages exposed to the sea-breezes have no spleen rate at all." Emphasis is also laid on that ubiquitous evil, the "borrow" pits along the railway track. Under existing conditions the only practical policy recommended is the abolition of these pits, the exposure of villages to sea breezes by the cutting down of grass and undergrowth, the institution of travelling dispensaries, and the proper control of new building schemes. A general attack on breeding-grounds in rural districts seems impossible. Certain areas of the island are free from malaria, and development should be recommended in these. The question of rice fields and malaria is one of first-rate importance. It would appear that we can get in a rice cultivation area three conditions :-( $x$ ) Healthy: spleen rate, 4.3 per cent.; (2) malaria endemic: 24.1 per cent.; (3) malaria hyperendemic: 